\title{
Determination of Linkages of Linear and Branched Oligosaccharides Using Closed-Ring Chromophore Labeling and Negative Ion Trap Mass Spectrometry
}

\author{
Hsing Ling Cheng and Guor Rong Her \\ Department of Chemistry, National Taiwan University, Taipei, Taiwan
}

\begin{abstract}
Linear as well as branched oligosaccharides were labeled with p-aminobenzoic ethyl ester (ABEE) using the glycosylamine closed-ring labeling approach and analyzed by negative-ion electrospray ionization mass spectrometry (ESI-MS). Linkage specific fragment ions of ABEE labeled linear oligosaccharides were proposed based on the $\mathrm{MS}^{2}$ and $\mathrm{MS}^{3}$ data for several ABEE labeled linear oligosaccharides with known linkage configurations. Fragmentation at the reducing end was similar to that observed for ABEE disaccharides whereas the fragmentation pattern not involving the reducing end was similar to underivatized disaccharides. Based on these ions, all the linkages of linear oligosaccharides could be unambiguously determined. The fragmentation pattern at the branched sugar was in general not quite the same as the linear one. However, many linkage specific fragment ions were also observed for linkages at the branched sugar. These ions along with the ions proposed for linear oligosaccharides were found to be quite useful for the determination of all the linkages of branched oligosaccharides. (J Am Soc Mass Spectrom 2002, 13, 1322-1330) (C 2002 American Society for Mass Spectrometry
\end{abstract}

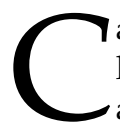
arbohydrates are widely distributed and play a key role in numerous biological processes, such as protein conformation, molecular recognition, and cellular interaction [1, 2]. It appears that variations of glycan patterns such as fucosylation [3] or sialylation $[4,5]$ are crucial and have direct implications to carbohydrate biological activity. To fully understand the specific functions of the glycoconjugates, a detailed characterization of glycan structure is necessary.

Mass spectrometry has become one of the most powerful and versatile techniques for structural analysis of carbohydrates. It provides many advantages over traditional analytical methods [6], such as low sample consumption and high sensitivity. In the past few years, soft ionization techniques such as matrix-assisted laser desorption/ionization (MALDI) and electrospray ionization (ESI) have been used for linkage and sequence determination of oligosaccharides [7-25]. Underivatized oligosaccharides have frequently been analyzed by MALDI $[7,8]$. In contrast, metal ion coordinated $[9,10]$ or chemically derivatized 11-23v] oligosaccharides have been employed for ESI.

The most common derivatization technique is reductive amination. The formation of chromophore-labled derivatives simultaneously enhances HPLC separation

Published online September 30, 2002

Address reprint requests to Dr G.-R. Her, Department of Chemistry, National Taiwan University, 10764 Taipei, Taiwan. E-mail: grher@ccms.ntu.edu.tw efficiency, MS ionization efficiency, and detection by conventional HPLC detectors. Sensitivity enhancement has been reported for several derivatives including 2-aminopyridine (2-AP) [26, 27], 4-aminobenzoic acid ethyl ester (ABEE) [27, 28], and trimethyl-(4-aminophenyl)amino (TMAPA) [27, 29].

Our earlier studies [21-23] suggested that closedring derivatives (glycosylamines) provide greater structural information on linkage and anomeric configuration than open-ring (reductive amination) products under negative-ion $\mathrm{FAB} /$ collision-induced dissociation (CID), ESI-in-source CID, and ESI-MS/MS. In addition, closed-ring derivatives have shown better chromatographic behavior than open-ring derivatives on an amine HPLC column [20, 21]. Our earlier ESI-MS/MS study mainly focused on the linkage analysis of disaccharides [22]. In the present study, we have extended the study to a variety of linear and branched glycans. The utility and limitations of this approach are discussed.

\section{Experimental}

\section{Materials}

Ethyl 4-aminobenzoate (ABEE), maltoheptaose, 2mercaptoethanol, formic acid, trifluoroacetic acid (TFA), glacial acetic acid, sodium carbonate, dimethyl sulfoxide (DMSO), lacto-N-fucopentaose (LNFP-1), pepsin, 
Table 1. Structures of oligosaccharides

\begin{tabular}{|c|c|}
\hline LNT & Gal $\beta 1-3 \mathrm{GlcNAc} \beta 1-3 \mathrm{Gal} \beta 1-4 \mathrm{Glc}$ \\
\hline LNFP-1 & Fuc $\alpha 1-2 \mathrm{Gal} \beta 1-3 \mathrm{GlcNAc} \beta 1-3 \mathrm{Gal} \beta 1-4 \mathrm{Glc}$ \\
\hline PLA-1 & $\operatorname{Man} \alpha 1-6 \backslash_{\operatorname{Man} \beta 1-4 G I c N A c \beta 1-4 G I c N A c}$ \\
\hline PLA-3C & $\operatorname{Man} \alpha 1-3{ }^{\operatorname{Man} \alpha 1-6} \backslash_{\operatorname{Man} \beta 1-4 \mathrm{GlcNAc} \beta 1-4 \mathrm{GIcNAc}}$ \\
\hline PLA-3B & $\operatorname{Man} \beta 1-4 \mathrm{GIcNAc} \beta 1-4 \mathrm{GIcNAc}$ \\
\hline PLA-3A & $\begin{array}{c}\operatorname{Man} \beta 1-4 \mathrm{GIcNAc} \beta 1-4 \mathrm{GIcNAc} \\
\text { Fuc } \alpha 1-3\end{array}$ \\
\hline PLA-5A & 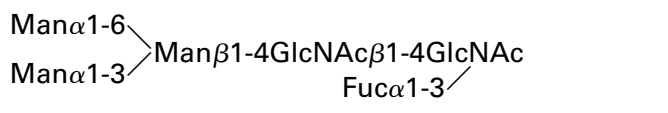 \\
\hline PLA-2 & $\operatorname{Man} \alpha 1-6 \backslash_{\operatorname{Man} \beta 1-4 G I c N A c \beta 1-4 G I c N A c}$ \\
\hline PLA-4B & 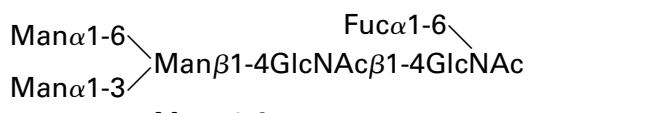 \\
\hline PLA-5B & 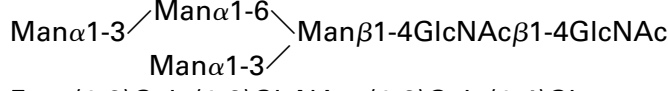 \\
\hline LNDFH & $\begin{array}{c}\text { Fuc } \alpha(1-2) \mathrm{Gal} \beta(1-3) \operatorname{GlcNAc} \beta(1-3) \mathrm{Gal} \beta(1-4) \mathrm{Glc} \\
\text { Fuc } \alpha(1-4)\end{array}$ \\
\hline
\end{tabular}

Phospholipase $\mathrm{A}_{2}$ (PLA), and the disaccharides were purchased from Sigma Chemical (St. Louis, MO). LactoN-tetraose (LNT), lacto-difucotetraose (LDFT), and lacto-N-difucohexaose (LNDFH) were obtained from Oxford GlycoSciences. Peptide-N-glycanase A (PNGase A), laminarihexaose, and isomaltohexaose were purchased from Seikagaku Kogyo (Tokyo, Japan). HPLC grade methanol and acetonitrile were obtained from LAB-SCAN Analytical Science (Labscan Ltd. Dublin, Ireland). Deionized (18M $\Omega$ ) water (Milli-Q water system, Millipore Inc., Bedford, MA) was used in the preparation of the samples and buffer solution. Prior to use, the buffer solution was filtered through a $0.45 \mu \mathrm{m}$ membrane filter (Gelman Sciences, Ann Arbor, MI).

\section{Sample Preparation}

Oligosaccharides were released from pepsin-digested glycopeptides of honeybee Phospholipase $\mathrm{A}_{2}$ (PLA) by means of PNGase A digestion [30, 31]. Glycan purification was obtained using graphitized carbon cartridges (Alltech Associates, UK) [31, 32].

All oligosaccharides (Table 1) were ABEE closed-ring labeled using the glycosylamine approach. Dried lyophilized oligosaccharides (100 pmol-10 nmol) were dissolved in a $15 \mu \mathrm{l}$ volume of $0.1 \mathrm{M}$ ABEE solution (2 $\mathrm{mg}$ of the solid dissolved in a 3: 7 ( $\mathrm{vol} / \mathrm{vol})$ mixture of glacial acetic acid and DMSO, respectively) in a clean Eppendorf tube. The solution was incubated at $90^{\circ} \mathrm{C}$ for $10 \mathrm{~h}$. The pure derivatives were isolated after passage through an Oasis cartridge (Waters, UK), followed by lyophilisation.

\section{HPLC-UV System}

The chromatographic system consisted of two model LC-10AD pumps (Shimadzu, Kyoto, Japan), an Accurate microflow mixer (LC Packings, San Francisco, CA) a Rheodyne model 7125 injection valve (Rheodyne, Cotati, CA) fitted with a $1 \mu$ l loop, and a Rainin Dynamax UV-C UV detector set at $305 \mathrm{~nm}$ Rainin, (Woburn, MA). Chromatograms were recorded on a Pentium-PC using SISC PC Integrator software (Scientific Information Service Corporation, Taipei, Taiwan).

HPLC analysis was performed on a reversed phase $\mathrm{C}_{18}$ column (1 mm i.d. $\times 15 \mathrm{~cm}$; particle size, $3.5 \mu \mathrm{m}$, Waters Associates, Miford, MA). The mobile phases were deionized water (solvent A) and methanol (solvent B). The flow rate was set at $40 \mu \mathrm{l} / \mathrm{min}$. The following elution conditions were used: (step 1) $80 \%$ A, $20 \%$ B equilibration conditions; (step 2) 20-50\% B over 60 min, linear gradient; (step 3) wash with $100 \%$ B for 10 min; (step 4) reequilibration for $15 \mathrm{~min}$.

\section{Mass Spectrometry}

Experiments were performed on a Finnigan LCQ ion trap mass spectrometer (Finnigan Corp., San Jose, CA) with the standard Finnigan ESI source in negative ion mode at a voltage of $-3.5 \mathrm{kV}$. Samples were infused by syringe pump at a rate of $3 \mu \mathrm{l} / \mathrm{min}$ and nebulized with dry nitrogen. The heated capillary was maintained at a temperature of $200{ }^{\circ} \mathrm{C}$ for all experiments. Helium was introduced as the buffer/collision gas. For mass-analyzer CID, relative collision energies of $10-70 \%$ were used in $\mathrm{MS}^{n}$ experiments. The maximum ion collection time was set at $180 \mathrm{~ms}$ and five microscans were summed per scan.

\section{Results and Discussion}

\section{Linear Oligosaccharides}

Laminarihexaose, maltoheptaose, and isomaltohexaose are 1-3, 1-4, and 1-6 linked linear oligosaccharides, respectively. They were labeled with ABEE using glycosylamine (closed-ring approach) and studied by negative ion ESI-MS ${ }^{2}$ and/or $\mathrm{MS}^{3}$. It was found that the fragmentation pattern of the first linkage (reducing end) was very similar to the fragmentation of ABEE closedring labeled disaccharides [22]. For linkages other than the reducing end, the fragmentation patterns were similar, but not identical to, underivatized disaccharides $[24,25]$. A notable difference was the ${ }^{0,3} \mathrm{~A}_{2}$ ion (based on the nomenclature of Domon and Costello [33]) in 1-3 linked disaccharides [24, 25]. Unlike the underivatized 1-3 linked disaccharide, the ${ }^{0,3} \mathrm{~A}$ ions were not observed in laminarihexaose (a 1-3 linked oligosaccharide) even under the maximum collision energy (Figure 1). Based on the above study, fragment ions for linkage determination of linear oligosaccha- 

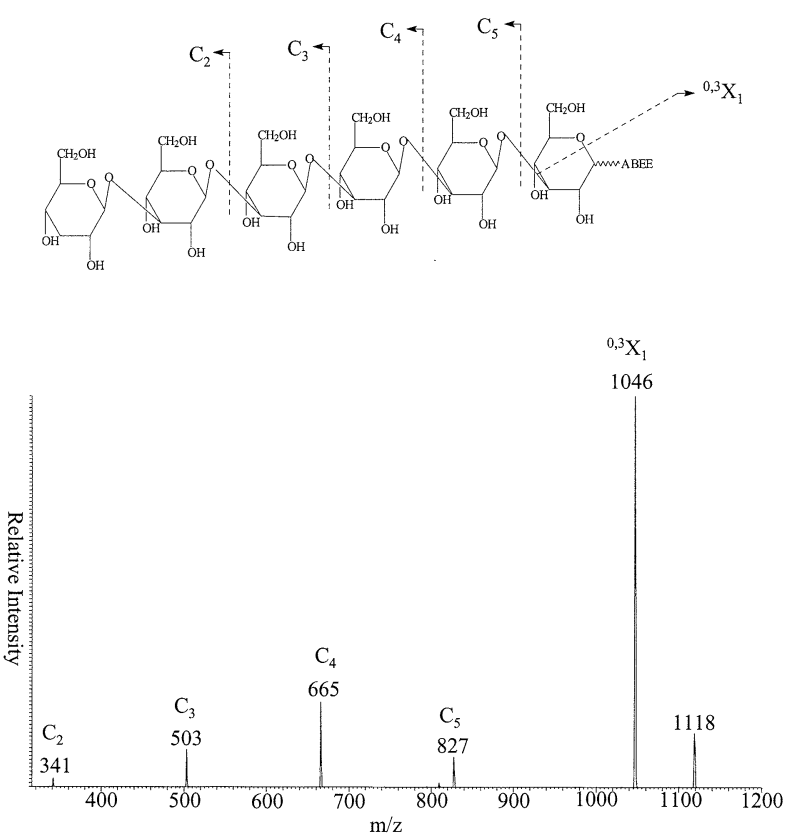

Figure 1. $\mathrm{MS}^{2}$ of the ABEE closed-ring labeled laminarihexaose, $m / z 1136$.

rides were proposed. These ions are summarized in Table 2.

The utility of the linkage specific ions in Table 2 was examined for linear oligosaccharides having more than one type of linkage: LNT, LNFP-1, PLA-1, and PLA-3C. Both LNT and LNFP-1 were derived from human milk. LNT is a tetrasaccharide with linkages of 1-4, 1-3, 1-3 from the reducing end. The linkages of the pentasaccharide, LNFP-1, are 1-4, 1-3, 1-3, and 1-2 from the reducing end. PLA-1 and PLA-3C were cleaved from the glycoprotein-PLA. PLA-1 is a tetrasaccharide with a linkage sequence of 1-4, 1-4, 1-6 from the reducing end whereas PLA-3C is a pentasaccharide with a linkage sequence of 1-4, 1-4, 1-6, 1-3 from the reducing end.

\section{LNT}

The $\mathrm{MS}^{2}$ spectrum of the ABEE closed-ring labeled LNT is shown in Figure 2a. The observation of the 1-4 linked

Table 2. Specific linkage fragment ions for ABEE closed-ring labeled linear oligosaccharides

\begin{tabular}{lll}
\hline & $\begin{array}{c}\text { Fragments of the first } \\
\text { linkage (reducing end) }\end{array}$ & \multicolumn{1}{c}{$\begin{array}{c}\text { Fragments other than } \\
\text { the reducing end }\end{array}$} \\
\hline \hline $1-2^{*}$ & ${ }^{0,2} X,{ }^{0,4} \mathrm{X}$ & $\mathrm{C}-18,{ }^{0,4} \mathrm{~A}-18,{ }^{1,3} \mathrm{~A}$ \\
$1-3$ & ${ }^{0,3} \mathrm{X}$ & No cross-ring fragments \\
$1-4$ & ${ }^{0,2} \mathrm{~A}-18$ & ${ }^{0,2} \mathrm{~A},{ }^{0,2} \mathrm{~A}-18$ \\
$1-6$ & ${ }^{0,3} \mathrm{~A}$ & $\mathrm{C}-18,{ }^{0,2} \mathrm{~A},{ }^{0,3} \mathrm{~A},{ }^{0,4} \mathrm{~A}$ \\
\hline
\end{tabular}

(*) Due to the lack of 1-2 linked standards, fragments of the first linkage were proposed based on the ABEE labeled 1-2 linked disaccharide. The fragments other than the reducing end were proposed based on the ABEE labeled LDFT. LDFT :

Fuc $\alpha 1-2 \mathrm{Gal} \beta 1-4 \mathrm{Glc}$.

Fuc $\alpha 1-3$
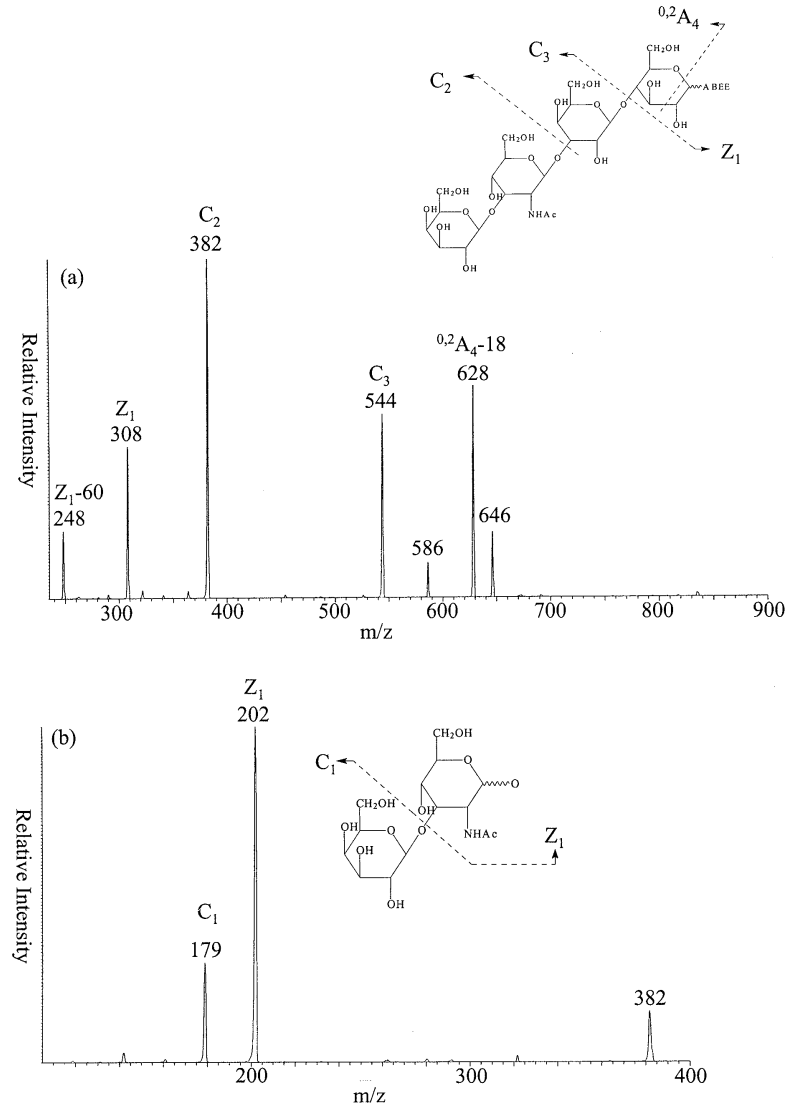

Figure 2. (a) $\mathrm{MS}^{2}$ of the ABEE closed-ring labeled LNT, $m / z 853$. (b) $\mathrm{MS}^{3}$ of the ABEE closed-ring labeled LNT, $m / z$ 853 $\rightarrow 382 \rightarrow$.

diagnostic ion at $m / z 628\left({ }^{0,2} \mathrm{~A}_{4}-18\right)$ suggested that the first linkage was a 1-4 linkage. The absence of cross-ring cleavage ions between $C_{3}(m / z 544)$ and $C_{2}(m / z ~ 382)$ suggested that the second glycosidic bond was 1-3 linked. Fragment ions for the last linkage were not detected in Figure 2a because, with the ion trap mass spectrometer, only fragments with $\mathrm{m} / \mathrm{z}$ values exceeding $28 \%$ of the precursor ion could be detected. To provide the information of the last linkage, the $C_{2}$ ion was selected for a $\mathrm{MS}^{3}$ experiment as shown in Figure $2 b$. In Figure $2 b$, the lack of cross-ring cleavage ions indicated that the third linkage was also a 1-3 linkage. With the information provided by the $\mathrm{MS}^{2}$ and $\mathrm{MS}^{3}$, the linkage sequence of 1-4, 1-3, 1-3 was assigned for LNT.

\section{LNFP-1}

The $\mathrm{MS}^{2}$ spectrum of the ABEE closed-ring labeled LNFP-1 is shown in Figure 3a. The ${ }^{0,2} \mathrm{~A}_{5}-18(\mathrm{~m} / \mathrm{z} 774)$ ion indicated a 1-4 linkage for the first linkage from the reducing end. The lack of cross-ring fragment ion between $\mathrm{m} / \mathrm{z} 690\left(\mathrm{C}_{4}\right)$ and $\mathrm{m} / \mathrm{z} 325\left(\mathrm{C}_{2}\right)$ suggested that the second and third linkages were 1-3 linkage. Due to the low-mass cutoff, the information of the terminal linkage was missing. To determine the terminal linkage, the $\mathrm{C}_{2}$ ion at $m / z 325$ was selected for $\mathrm{MS}^{3}$. The results from this experiment are shown in Figure $3 b$. The ions 


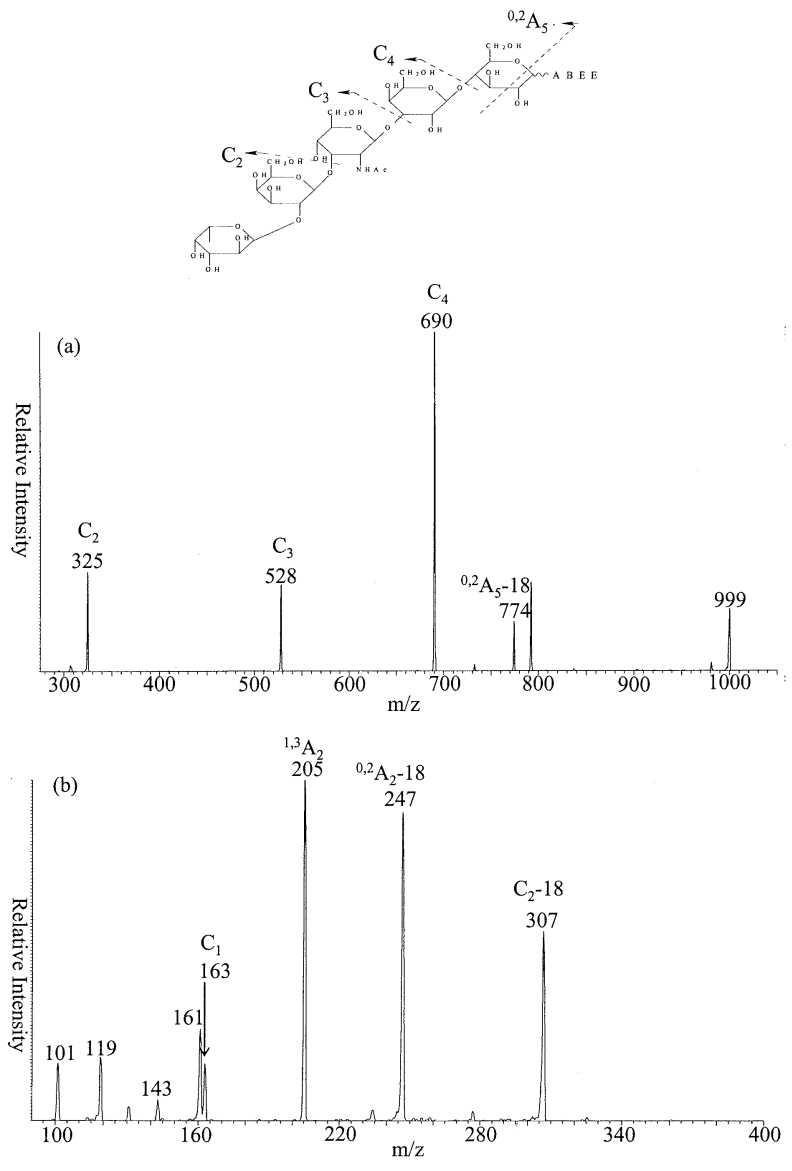

Figure 3. (a) $\mathrm{MS}^{2}$ of the ABEE closed-ring labeled LNFP-1, $\mathrm{m} / \mathrm{z}$ 999. (b) $\mathrm{MS}^{3}$ of the ABEE closed-ring labeled LNFP-1, $\mathrm{m} / \mathrm{z}$ 999 $\rightarrow$ $325 \rightarrow$.

at $m / z 307\left(\mathrm{C}_{2}-18\right), 247\left({ }^{0,4} \mathrm{~A}_{2}-18\right)$, and $205\left({ }^{1,3} \mathrm{~A}_{2}\right)$ indicated that the terminal linkage was a 1-2 linkage. Based on these two spectra, the linkage sequence of LNFP-1 was assigned as 1-4, 1-3, 1-3, and 1-2.

\section{PLA-1}

On-line HPLC/MS, HPLC/MS ${ }^{2}$, and/or $\mathrm{HPLC} / \mathrm{MS}^{3}$ were employed to study the glycans cleaved from the glycoprotein-PLA. Total ion current chromatograms (TIC) and selected ion chromatograms of the ABEE closed-ring labeled PLA glycans are shown in Figure 4. The separation efficiency was in general similar to that found for the reductive amination derivatives [31]. However, it was noteworthy that, using the closed-ring labeling reaction, a much better separation was obtained for the isobaric oligosaccharides, PLA-3B (a branched oligosaccharide) and PLA-3C (a linear oligosaccharide).

The $\mathrm{MS}^{2}$ spectrum of the ABEE closed-ring labeled PLA-1 is shown in Figure 5a. The $m / z 628\left({ }^{0,2} \mathrm{~A}_{4}-18\right)$ ion indicated that the first linkage was a 1-4 linkage. The $m / z 443\left({ }^{0,2} \mathrm{~A}_{3}\right)$ and $m / z 425\left({ }^{0,2} \mathrm{~A}_{3}-18\right)$ ions suggested that the second linkage was also a 1-4 linkage. To determine the terminal linkage, the ion at $m / z 341\left(\mathrm{C}_{2}\right.$ ion) was

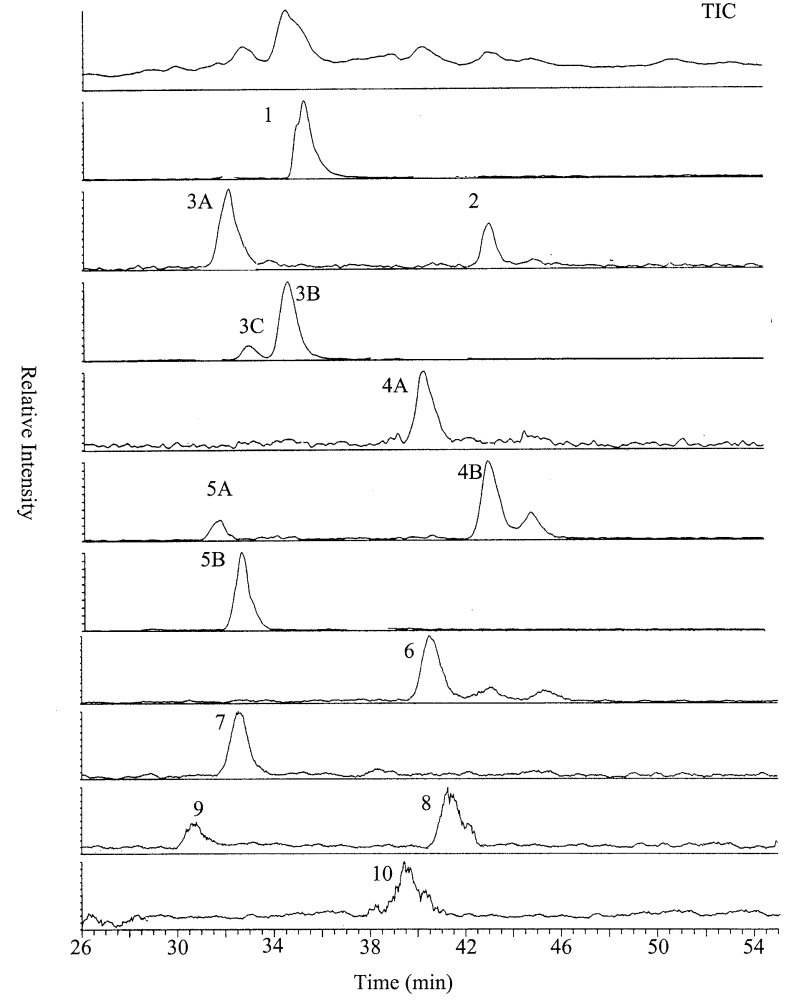

Figure 4. TIC and reconstructed ion chromatograms of the ABEE closed-ring labeled PLA glycan mixtures on a C-18 column $(150 \times$ $1 \mathrm{~mm}$ ) with $20-50 \%$ methanol-water as eluent at $40 \mu \mathrm{l} / \mathrm{min}$ with a $60 \mathrm{~min}$ program.

selected for a $\mathrm{MS}^{3}$ experiment $(894 \rightarrow 341 \rightarrow)$. The $\mathrm{MS}^{3}$ spectrum is shown in Figure $5 \mathrm{~b}$. The presence of the ions at $m / z 323\left(\mathrm{C}_{2}-18\right), m / z 281\left({ }^{0,2} \mathrm{~A}_{2}\right), m / z 251\left({ }^{0,3} \mathrm{~A}_{2}\right)$, and $m / z 221\left({ }^{0,4} \mathrm{~A}_{2}\right)$ suggested that the terminal linkage was a 1-6 linkage. Accordingly, a sequence of 1-4, 1-4, and 1-6 was assigned for PLA-1.

\section{PLA-3C}

The MS ${ }^{2}$ spectrum of the ABEE closed-ring labeled PLA-3C is shown in Figure 6a. The ion at $\mathrm{m} / \mathrm{z} 790$ $\left.{ }^{0,2} \mathrm{~A}_{5}-18\right)$ suggested a 1-4 linkage for the first linkage. The characteristic ions at $m / z 605\left({ }^{0,2} \mathrm{~A}_{4}\right)$ and $m / z 587$ $\left({ }^{0,2} \mathrm{~A}_{4}-18\right)$ indicated that the second linkage was also 1-4 linked. The $m / z 485\left(\mathrm{C}_{3}-18\right), \mathrm{m} / \mathrm{z} 443\left({ }^{0,2} \mathrm{~A}_{3}\right), \mathrm{m} / \mathrm{z}$ $413\left({ }^{0,3} \mathrm{~A}_{3}\right)$, and $m / z 383\left({ }^{0,4} \mathrm{~A}_{3}\right)$ ions suggested that the third linkage was a 1-6 linkage. The MS $^{3}$ spectrum of the $C_{3}(m / z 503)$ ion (Figure 6b) made it possible to assign the terminal linkage. The absence of cross-ring cleavage ions below $\mathrm{m} / \mathrm{z} 341$ indicated that the nonreducing end was a 1-3 linkage. The ions at $m / z 485$ $\left(\mathrm{C}_{3}-18\right), m / z 443\left({ }^{0,2} \mathrm{~A}_{3}\right), m / z 413\left({ }^{0,3} \mathrm{~A}_{3}\right)$, and $m / z 383$ $\left({ }^{0,4} \mathrm{~A}_{3}\right)$ again suggested that the third linkage was 1-6 linked. Based on these two spectra, the linkage sequence of PLA-3C was assigned as 1-4, 1-4, 1-6 and $1-3$. 


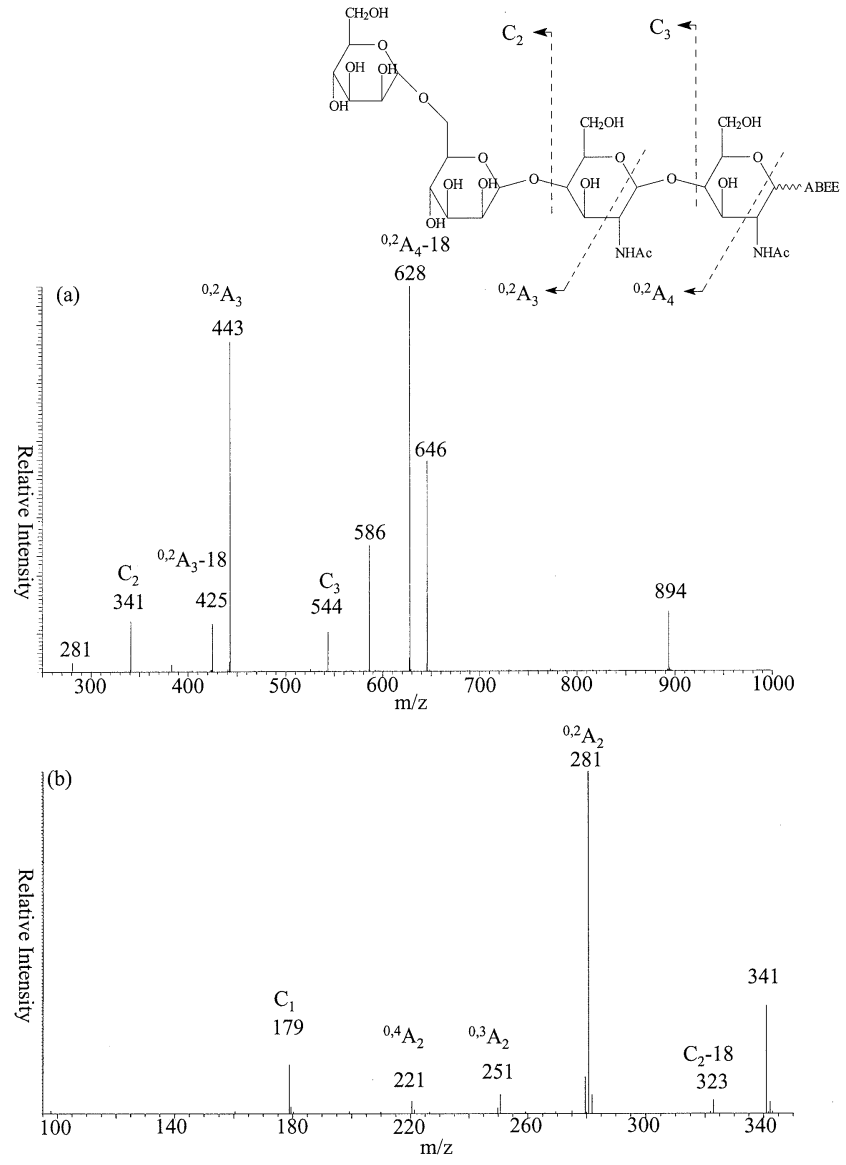

Figure 5. (a) $\mathrm{MS}^{2}$ of the ABEE closed-ring labeled PLA-1, $\mathrm{m} / \mathrm{z}$ 894. (b) $\mathrm{MS}^{3}$ of the ABEE closed-ring labeled PLA-1, $\mathrm{m} / \mathrm{z} 894 \rightarrow$ $341 \rightarrow$.

\section{Branched Oligosaccharides}

The study of the four linear oligosaccharides with more than one type of linkage suggested that the linkage diagnostic ions proposed in Table 2 are quite useful to assign the linkages of linear oligosaccharides. Several branched oligosaccharides of PLA glycoprotein were subsequently studied. The mass spectra of these branched oligosaccharides suggested that the fragmentation pattern of branched sugars was modified relative to the pattern documented for linear sugars. In order to establish a strategy for the analysis of linear and branched sugars, several branched oligosaccharides were studied with negative-ion ESI-MS ${ }^{2}$ and/or MS $^{3}$.

\section{1-3 and 1-6 Linked Branched Sugars}

PLA-3B is an isobaric oligosaccharide of PLA-3C. It is a branched oligosaccharide with a 1-3 and a 1-6 linkage at the branched sugar. The $\mathrm{MS}^{2}$ spectrum of the ABEE closed-ring labeled PLA-3B is shown in Figure 7a. There are four linkages in PLA-3B. The presence of the $m / z 790$ $\left({ }^{0,2} \mathrm{~A}_{4}-18\right)$ ion indicated that the first linkage was a 1-4 linkage. The ions at $m / z 605\left({ }^{0,2} \mathrm{~A}_{3}\right)$ and $m / z 587\left({ }^{0,2} \mathrm{~A}_{4}-18\right)$ suggested that the second linkage was also a 1-4 linkage. The data in Figure 7a did not contain information
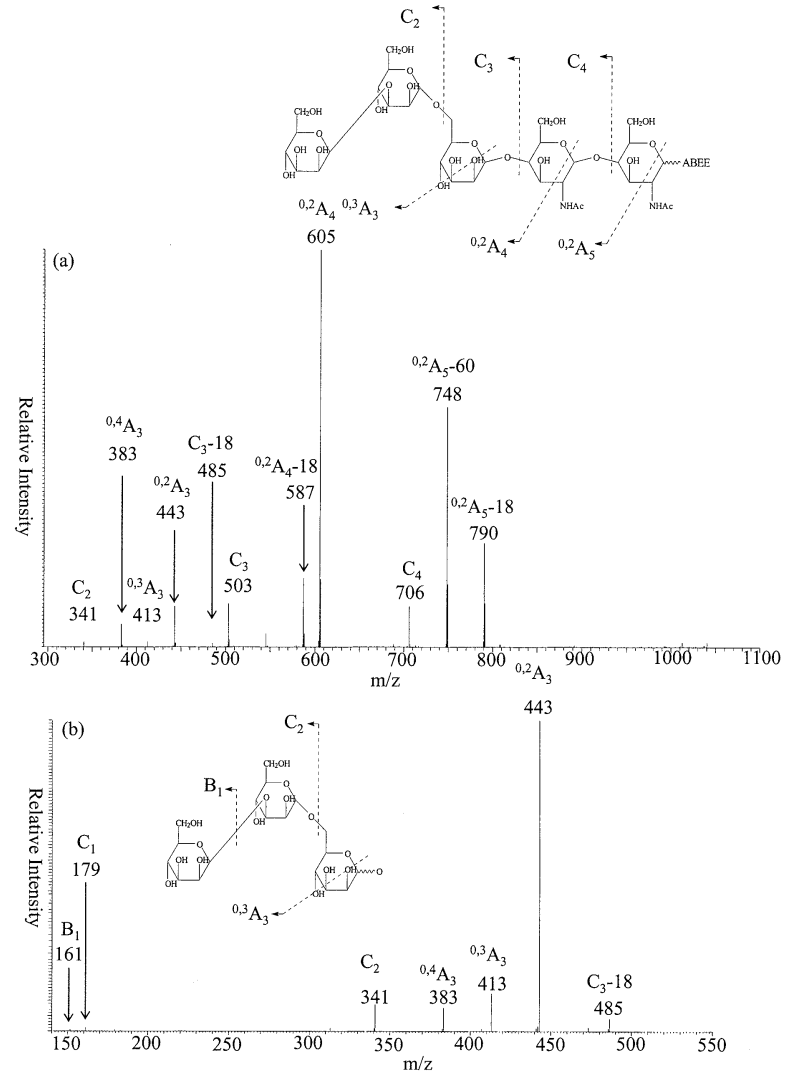

Figure 6. (a) $\mathrm{MS}^{2}$ of the ABEE closed-ring labeled PLA-3C, $\mathrm{m} / \mathrm{z}$ 1056. (b) $\mathrm{MS}^{3}$ of the ABEE closed-ring labeled PLA-3C, $m / z 1056 \rightarrow$ $503 \rightarrow$.

for the two linkages at the branched sugar. The $m / z 503$ $\left(C_{2}\right)$ ion is the fragment of the branched trisaccharide and the $m / z 323\left(C_{2} / Z_{3 x}-H\right)$ ion corresponds to a disaccharide ion resulting from the loss of a monosaccharide from the $\mathrm{m} / \mathrm{z} 503$ trisaccharide ion. The CID of the $\mathrm{m} / \mathrm{z}$ 323 ion (Figure $7 \mathrm{~b}$ ) suggested that the linkage was most likely a 1-6 linkage because, with the exception of the ${ }^{0,2} \mathrm{~A}$ ion, the characteristic 1-6 linked ions at $\mathrm{C}_{2}-18(\mathrm{~m} / \mathrm{z}$ 305), ${ }^{0,3} \mathrm{~A}_{2}(\mathrm{~m} / \mathrm{z} 251)$, and ${ }^{0,4} \mathrm{~A}_{2}(\mathrm{~m} / \mathrm{z} 221)$ were observed. As mentioned earlier, the $\mathrm{m} / \mathrm{z} 323$ ion was produced from the loss of a monosaccharide from the terminal 1-3 and 1-6 linked branched trisaccharide. The assignment of a 1-6 linkage suggested that the other linkage is a 1-3 linkage and the 1-3 linked monosaccharide was easily cleaved from the trisaccharide. Based on this observation, the loss of a hexose $(\mathrm{m} / \mathrm{z} 503 \rightarrow 323 \rightarrow)$ was proposed for the determination of a branched 1-3 linkage (Table 3). The absence of the ${ }^{0,2} \mathrm{~A}$ ion in the 1-6 linkage is consistent with the fact that the hydroxyl group at the 3-position is substituted with a monosaccharide.

\section{1-3 and 1-4 Linked Branched Sugars}

PLA-3A is $\alpha 1-3$ fucosylated at the Asn-linked GlcNAc. The $\mathrm{MS}^{2}$ spectrum of the ABEE closed-ring labeled PLA-3A is shown in Figure 8. The ion at $\mathrm{m} / \mathrm{z} 774$ $\left({ }^{0,2} \mathrm{~A}_{4}-18\right)$ suggested a 1-4 linkage at the reducing end. 


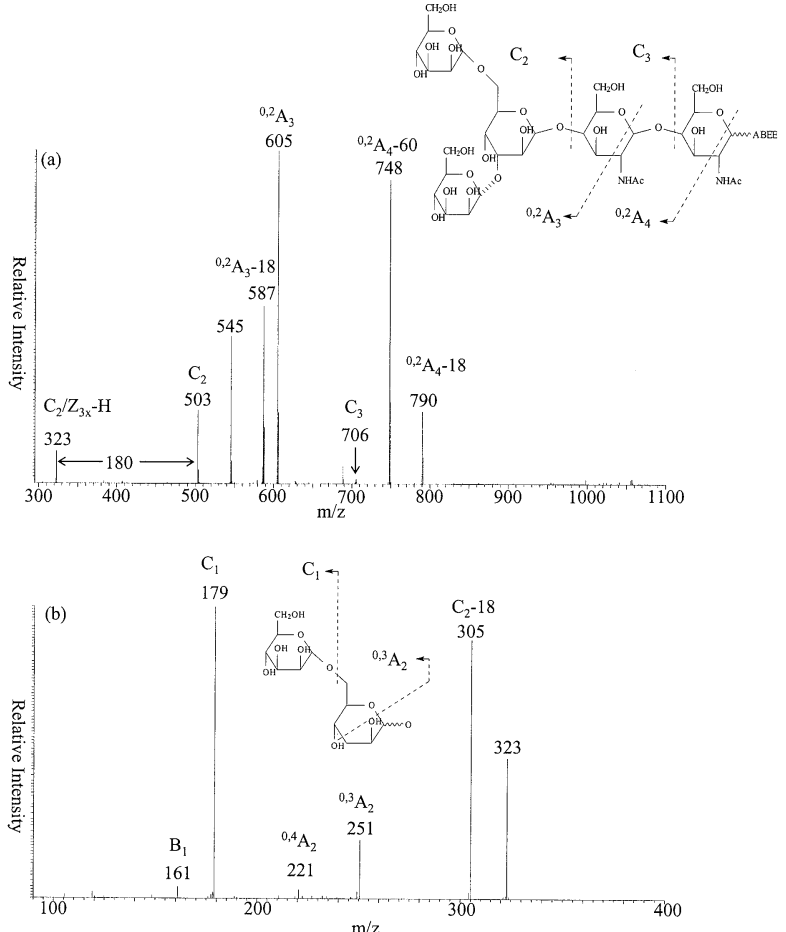

Figure 7. (a) $\mathrm{MS}^{2}$ of the ABEE closed-ring labeled PLA-3B, $\mathrm{m} / \mathrm{z}$ 1056). (b) $\mathrm{MS}^{3}$ of the ABEE closed-ring labeled PLA-3B, $m / z 1056 \rightarrow$ $323 \rightarrow$.

The ion at $m / z 876\left(\mathrm{Z}_{1 \beta}-\mathrm{H}\right)$ represents the loss of a fucose (164 Da) from the precursor ion $(m / z$ 1040). This observation is similar to the 1-3 and 1-6 linked branched sugar; the 1-3 linked hexose is easily cleaved from the 1-3 and 1-4 linked branched sugar. Support for the 1-4 linkage assignment at the branched point comes from the ${ }^{0,2} \mathrm{~A}-18$ ion (as in the linear sugar) as well as another specific ion, the $m / z 816\left({ }^{0,4} \mathrm{X} / \mathrm{Z}_{1 \beta}-\mathrm{H}\right)$ ion indicating that the linkages at the branched point are 1-3 and 1-4 linked for this sugar.

Like PLA-3A, PLA-5A is also $\alpha 1-3$ fucosylated at the Asn-linked GlcNAc. The $\mathrm{MS}^{2}$ spectrum of the ABEE closed-ring labeled PLA-5A is shown in Figure 9. As expected, a 1-3 linkage at the branched point was revealed by the detection of the $Z_{1 \beta}-H$ ion $(m / z$ 1038). This ion corresponds to the loss of a fucose from the molecular ion. The ${ }^{0,2} \mathrm{~A}_{4}-18$ ion at $m / z 936$ and the ${ }^{0,4} \mathrm{X}_{1} / \mathrm{Z}_{1 \beta}-\mathrm{H}$ fragment at $m / z 978$ suggested a 1-4 linkage in the 1-3 and1-4 linked branched sugar.

Table 3. Specific linkage fragment ions for linkages at the branched sugars

\begin{tabular}{lcl}
\hline Linkage & $\begin{array}{c}\text { The other linkage at } \\
\text { the branched point }\end{array}$ & $\begin{array}{c}\text { Fragments for linkages at } \\
\text { branch points }\end{array}$ \\
\hline \hline $1-3$ & $1-4$ & $\begin{array}{l}\text { Z-H (loss of hexose units) } \\
\text { Z-H (loss of hexose units) }\end{array}$ \\
$1-4$ & $1-6$ & $\begin{array}{l}0,2 \\
\text { A }-18,,^{0,4} \mathrm{X} / \mathrm{Z}-\mathrm{H}\end{array}$ \\
$1-6$ & $1-3$ & ${ }^{0,2} \mathrm{~A}-18$ \\
& $1-6$ & $\mathrm{C}-18,{ }^{0,3} \mathrm{~A},{ }^{0,4} \mathrm{~A}$ \\
& $1-3$ & ${ }^{0,3} \mathrm{~A} / \mathrm{W}$ \\
\hline
\end{tabular}

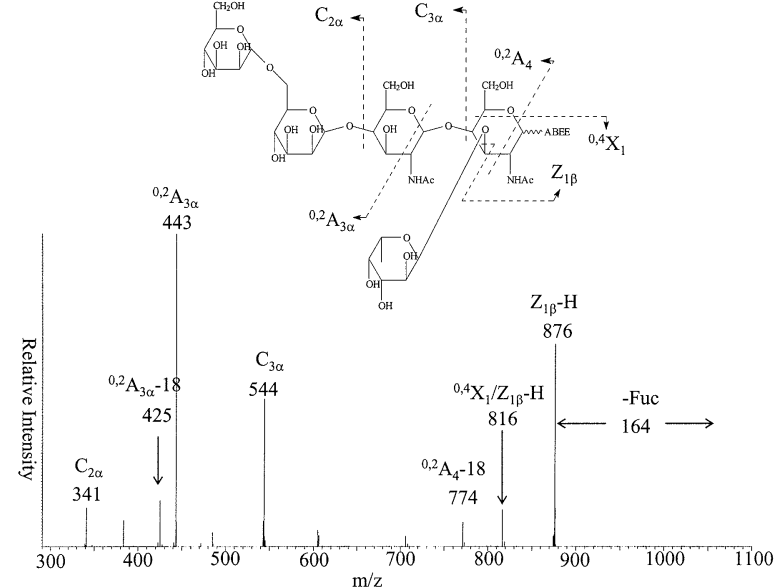

Figure 8. $\mathrm{MS}^{2}$ of the ABEE closed-ring labeled PLA-3A, $\mathrm{m} / \mathrm{z}$ 1040.

\section{1-4 and 1-6 Linked Branched Sugars}

PLA-2 is an oligosaccharide with a 1-4 and 1-6 linked branched sugar. The $\mathrm{MS}^{2}$ spectrum of the ABEE closedring labeled PLA-2 is shown in Figure 10. The characteristic ion for 1-4 linkage at the 1-4 and 1-6 branched point was found to be unchanged. The ${ }^{0,2} \mathrm{~A}_{4}-18$ ion at $\mathrm{m} / \mathrm{z} 774$ indicated that the reducing end contained a 1-4 linkage. However, unlike the linear 1-6 linkage, where the ${ }^{0,3} \mathrm{~A}_{4 \alpha}$ ion was observed, $\mathrm{a}^{0,3} \mathrm{~A}_{4 \alpha} / \mathrm{W}_{1 \beta}$ ion at $m / z 586$ was detected. The ${ }^{0,3} \mathrm{~A}_{4 \alpha} / \mathrm{W}_{1 \beta}$ fragment represents the loss of a fucose, $\mathrm{ABEE}$, and $\mathrm{C}_{6} \mathrm{H}_{7} \mathrm{NO}_{2}$ from the precursor ion. This specific fragmentation was also observed in the $\mathrm{MS}^{2}$ spectrum of PLA-4B (Figure 11). PLA-4B also has a fucose residue $\alpha 1-6$ linked to the innermost GlcNAc. In Figure 11, the ${ }^{0,3} \mathrm{~A}_{4 \alpha} / \mathrm{W}_{1 \beta}$ ion at $m / z 748$ was detected. Accordingly, the ${ }^{0,3} \mathrm{~A} / \mathrm{W}$ ion can be used to assign the 1-6 linkage for this 1-4 and 1-6 linked branched sugar.

Based on the above study, fragment ions for linkages at the branched point were proposed as shown in Table 3. The utility of Table 2 and Table 3 to determine all the

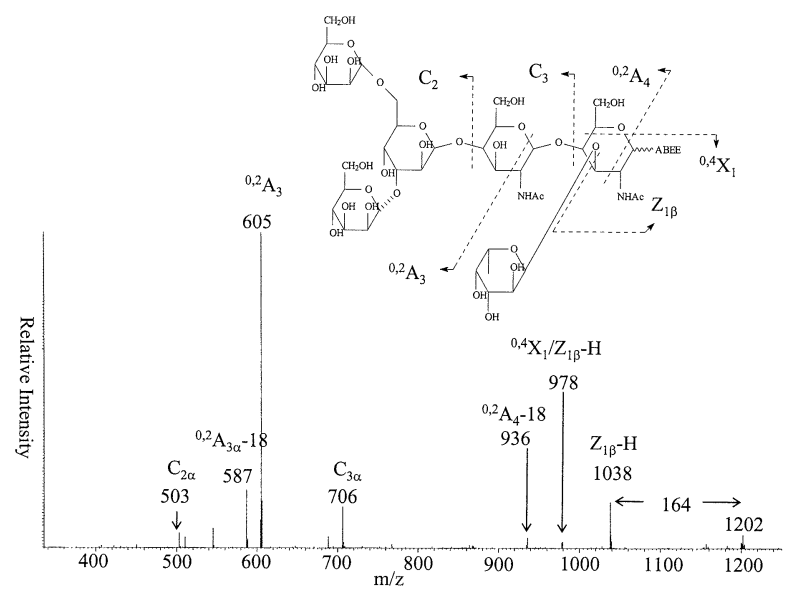

Figure 9. $\mathrm{MS}^{2}$ of the ABEE closed-ring labeled PLA-5A, $\mathrm{m} / \mathrm{z}$ 1202. 


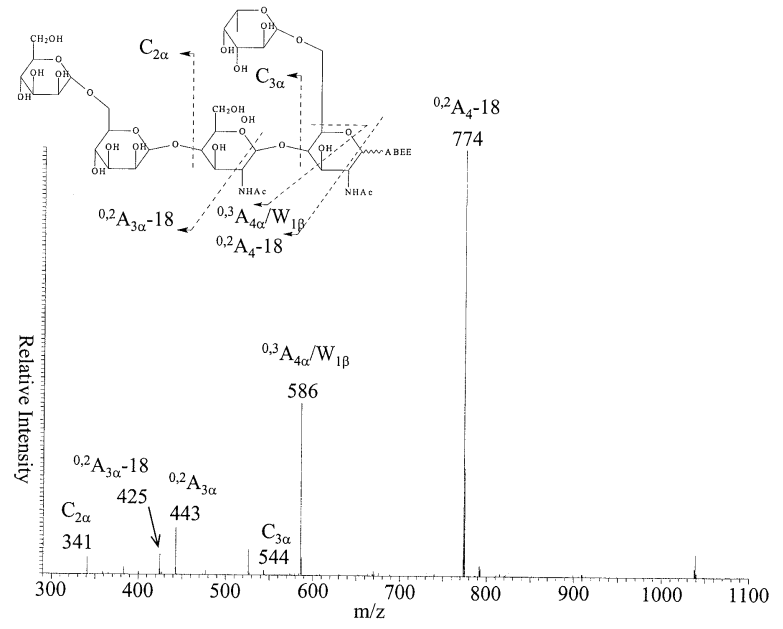

Figure 10. $\mathrm{MS}^{2}$ of the ABEE closed-ring labeled PLA-2, $\mathrm{m} / \mathrm{z}$ 1040.

linkages of branched oligosaccharides was verified with the oligosaccharides PLA-5B and LNDFH.

\section{PLA-5B}

PLA-5B was released from the glycoprotein PLA. The $\mathrm{MS}^{2}$ spectrum of the ABEE closed-ring labeled PLA-5B is shown in Figure 12a. The ion at $\mathrm{m} / \mathrm{z} 952\left({ }^{0,2} \mathrm{~A}_{5}-18\right)$ suggested a 1-4 linkage at the reducing end. The ions at $m / z 767\left({ }^{0,2} \mathrm{~A}_{4}\right)$ and $m / z 749\left({ }^{0,2} \mathrm{~A}_{4}-18\right)$ indicated that the second linkage was also a 1-4 linkage. The $m / z 485$ ion $\left(\mathrm{C}_{3} / \mathrm{Z}_{3 \beta}-\mathrm{H}\right)$ represents the loss of a hexose from the terminal tetrasaccharide $C_{3}$ ion $(\mathrm{m} / \mathrm{z} 665)$. The observation of the $m / z 485$ ion $\left(C_{3} / Z_{3 \beta}-H\right)$ suggests that there is a 1-3 linkage at the branched sugar. This $\mathrm{m} / \mathrm{z} 485$ trisaccharide ion was subsequently selected for a $\mathrm{MS}^{3}$ experiment to determe its linkages. The CID spectrum of the $m / z 485$ ion is shown in Figure 12b. The ions at

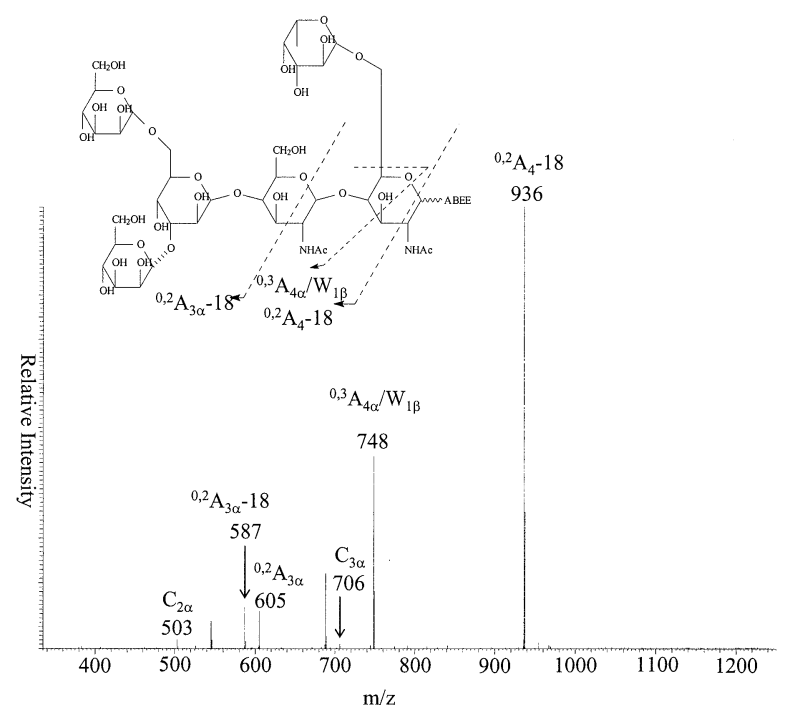

Figure 11. $\mathrm{MS}^{2}$ of the ABEE closed-ring labeled PLA- $4 \mathrm{~B}, \mathrm{~m} / \mathrm{z}$ 1202.

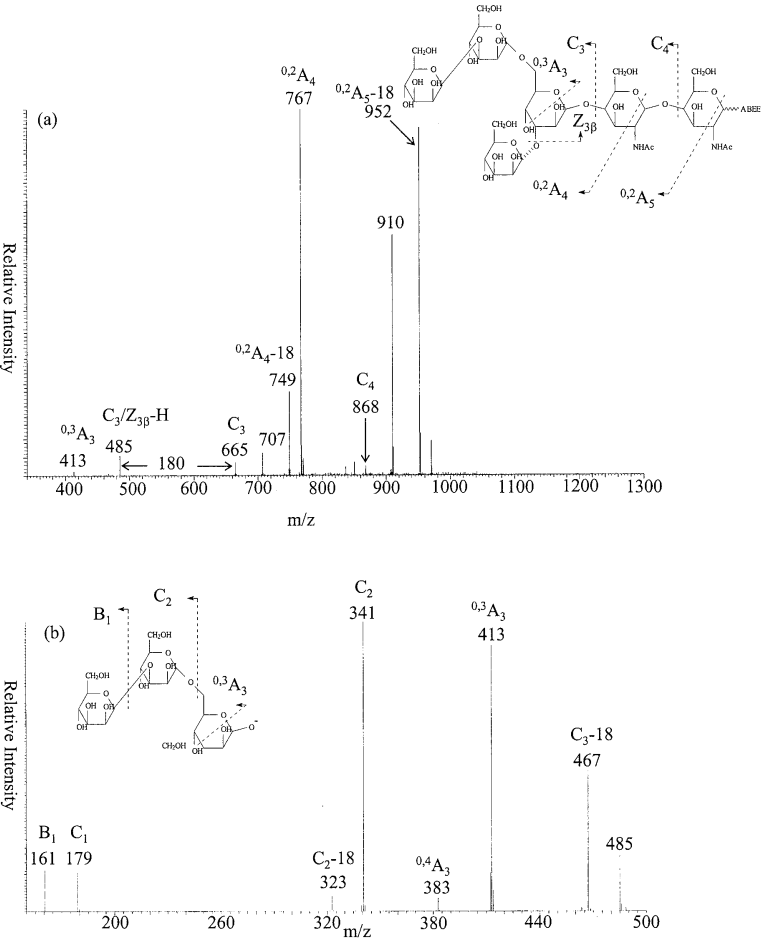

Figure 12. (a) $\mathrm{MS}^{2}$ of the ABEE closed-ring labeled PLA-5B, $\mathrm{m} / \mathrm{z}$ 1218. (b) $\mathrm{MS}^{3}$ of the ABEE closed-ring labeled PLA-5B, $\mathrm{m} / \mathrm{z} 1218 \rightarrow$ $485 \rightarrow$.

$m / z 467\left(\mathrm{C}_{3} / \mathrm{Z}_{3 \beta}-\mathrm{H}-18\right), m / z 413\left({ }^{0,3} \mathrm{~A}_{2}\right), m / z 383\left({ }^{0,4} \mathrm{~A}_{2}\right)$ and the absence of a ${ }^{0,2} \mathrm{~A}(\mathrm{~m} / \mathrm{z} 425)$ ion suggested that there was a 1-6 linkage at the 1-3 and 1-6 branched sugar. The observation of no cross-ring fragment below $\mathrm{m} / \mathrm{z} 341$ indicated a 1-3 linkage at the non-reducing end of the trisaccharide residue. With the information provided by the $\mathrm{MS}^{2}$ and $\mathrm{MS}^{3}$ spectra, all the linkages of the branched oligosaccharide were assigned.

\section{LNDFH}

LNDFH was derived from human milk. The $\mathrm{MS}^{2}$ spectrum of the ABEE closed-ring labeled LNDFH is shown in Figure 13. The ion at $m / z 920\left({ }^{0,2} \mathrm{~A}_{5}-18\right)$ suggested a 1-4 linkage at the reducing end. The lack of cross-ring fragment ions between $\mathrm{m} / \mathrm{z} 836\left(\mathrm{C}_{4}\right)$ and $\mathrm{m} / \mathrm{z} 674\left(\mathrm{C}_{3}\right)$ suggested that the second linkage was a 1-3 linkage. The ion at $m / z 348\left(\mathrm{C}_{3} / \mathrm{Z}_{3 \alpha}-\mathrm{H}\right)$ corresponds to the loss of a disaccharide unit (326 Da) from the tetrasaccharide $\mathrm{C}_{3}$ $(\mathrm{m} / \mathrm{z}$ 674) ion. This loss of a disaccharide residue from the tetrasaccharide indicated that the hydroxy group at the 3 position of the branched sugar was substituted with a disaccharide residue. The other linkage at the branched sugar was assigned by the $\mathrm{MS}^{3}$ spectrum of the $C_{3}(m / z 674)$ ion (Figure 14a). Besides the weak 1-4 linked diagnostic ion at $m / z 554\left({ }^{0,2} \mathrm{~A}_{3}-18\right)$, the presence of the ion at $m / z 288\left({ }^{0,4} \mathrm{X}_{1} / \mathrm{Z}_{1 \alpha}-\mathrm{H}\right)$ suggested a $1-4$ linkage at the 1-3 bound branched sugar. Selection of the $\mathrm{C}_{2}(\mathrm{~m} / \mathrm{z} 325)$ ion for $\mathrm{MS}^{3}$ provided the information of the terminal linkage. The $\mathrm{MS}^{3}$ spectrum is shown in Figure $14 \mathrm{~b}$. The ions at $\mathrm{m} / \mathrm{z} 307\left(\mathrm{C}_{2}-18\right), 247\left({ }^{0,4} \mathrm{~A}_{2}\right)$, and 


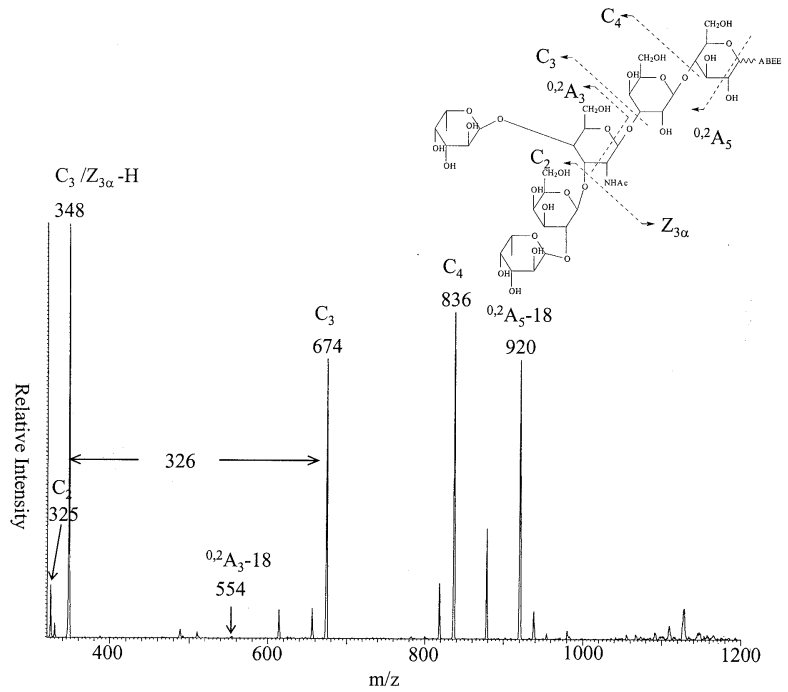

Figure 13. $\mathrm{MS}^{2}$ of the ABEE closed-ring labeled $\mathrm{LNDFH}, \mathrm{m} / \mathrm{z}$ 1146.

$205\left({ }^{1,3} \mathrm{~A}_{2}\right)$ suggested that the linkage at the non-reducing end was a 1-2 linkage. Based on $\mathrm{MS}^{2}$ and $\mathrm{MS}^{3}$ spectra, all the linkages of LNDFH were determined.
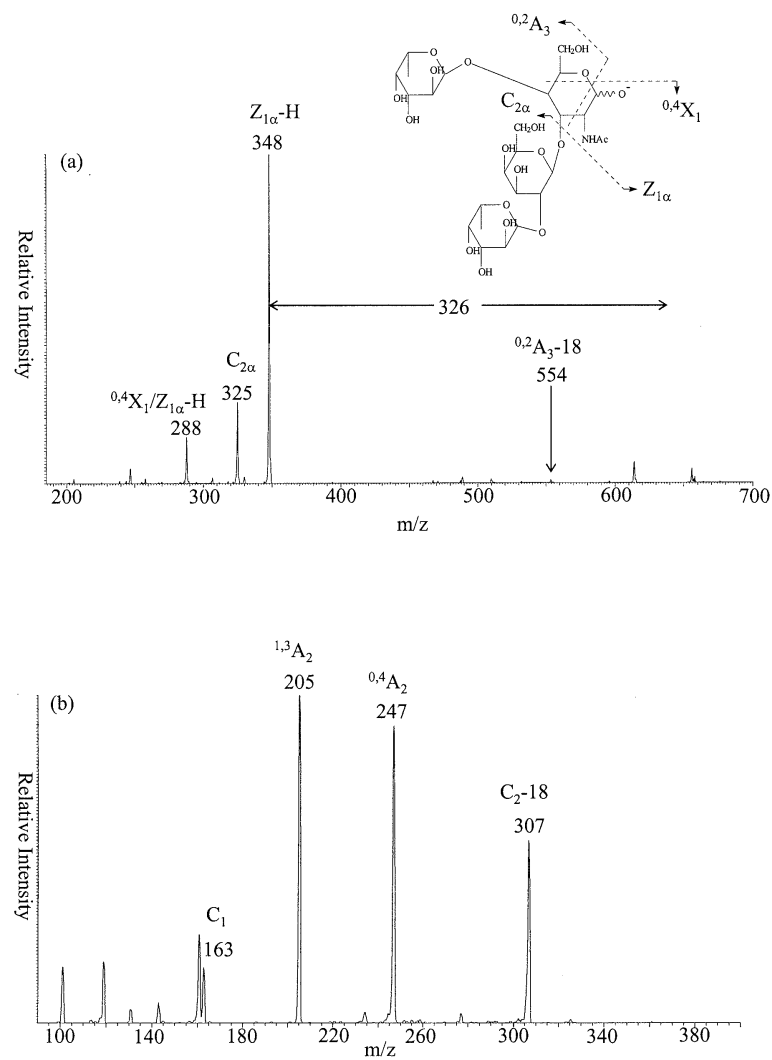

Figure 14. (a) $\mathrm{MS}^{3}$ of the ABEE closed-ring labeled LNDFH, $m / z$ $1146 \rightarrow 674 \rightarrow$. (b) $\mathrm{MS}^{3}$ of the ABEE closed-ring labeled LNDFH, $m / z 1146 \rightarrow 325 \rightarrow$.

\section{The Effects of Sample Purity and Monosaccharide} Composition

The assignment of 1-3 linkage is based on the absence of fragment ions. This may create a problem if an isobaric oligosaccharide of different linkage is mixed with the target compound. For example, the observation of 1-6 linked characteristic ions cannot eliminate the possibility that a 1-3 isobaric impurity is also present in the sample. Consequently, the purity of the sample is important in the assignment of linear linkage. The purity of the sample is believed to be not important to the assignment of branch point. The characteristic ions for the three different branched sugars (1-3 1-4, 1-3 1-6, 1-4 1-6) are quite different so that an isobaric mixture containing more than one type of branched sugars could be unambiguously assigned.

All the interpretations were based solely on the difference in linkage. Our earlier study [23] suggests that anomeric configuration and monosaccharide compositions have little effect on the fragmentation of disaccharide. However, clear conclusions on monosaccharide composition and anomeric configuration to the fragmentation of oligosaccharides could not be drawn because of the lack of oligosaccharide standards with all possible combinations.

\section{Conclusions}

Extended from the study of negative-ion ESI-MS ${ }^{2}$ of closed-ring labeled disaccharides, a new strategy for linkage determination of linear and branched oligosaccharides was proposed. For linear oligosaccharides, the fragmentation pattern of the first linkage was similar to that of the closed-ring labeled disaccharides whereas the fragmentation pattern of other linkages was similar to that of underivatized disaccharides. Linkage specific ions were tabulated (Table 2) for the linkage analysis of closed-ring labeled linear oligosaccharides. In general, linkage specific fragments at branch points were not quite the same as the linear ones. Consequently, Table 3 was introduced to determine the linkages at the branch point. Based on the linkage specific fragment ions in Table 2 and Table 3, all the linkages of branched oligosaccharides analyzed in this study were unambiguously confirmed. Currently, we are investigating the utility of this approach to oligosaccharides larger than hexasaccharides.

\section{Acknowledgments}

This work was supported by the National Research Council of the Republic of China.

\section{References}

1. Li, H.; Sharon, N. Protein Glycosylation: Structural and Functional Aspects. Eur. J. Biochem. 1993, 218(1), 1-27.

2. Varki, A. Biological Roles of Oligosaccharides: All of the Theories are Correct. Glycobiol. 1993, 3(2), 97-130. 
3. Staudacher, E.; Altmann, F.; Wilson, I. B. H.; Marz, L. Fucose in N-Glycans: From Plant to Man. Biochim. Biophys. Acta. 1999, 1473(1), 216-236.

4. Linsley, K. B.; Chan, S. Y.; Chan, S.; Reinhold, B. B.; Lisi, P. J.; Reinhold, V. N. Applications of Electrospray Mass Spectrometry to Erythropoietin N- and O-Linked Glycans. Anal. Biochem. 1994, 219(2), 207-217.

5. Sasaki, H.; Bothner, B.; Dell, A.; Fukuda, M. Carbohydrate Structure of Erythropoietin Expressed in Chinese Hamster Ovary Cells by a Human Erythropoietin cDNA. J. Biol. Chem. 1987, 262(25), 12059-12076.

6. Chaplin, M. F.; Kennedy, J. F. Carbohydrate Analysis. Oxford University, Inc: New York, 1994; pp 221-289.

7. Harvey, D. J.; Küster, B.; Naven, T. J. P. Perspectives in the Glycosciences-Matrix-Assisted Laser Desorption/Ionization (MALDI) Mass Spectrometry of Carbohydrates. Glycoconjugate J. 1998, 15(4), 333-338.

8. Tseng, K.; Hedrick, J. L.; Lebrilla, C. B. Catalog-Library Approach for the Rapid and Sensitive Structural Elucidation of Oligosaccharides. Anal. Chem. 1999, 71, 3747-3754.

9. Sible, E. M.; Brimmer, S. P.; Leary, J. A. Interaction of First Row Transition Metals with a 1-3, a 1-6 Mannotriose, and Conserved Trimannosyl Core Oligosaccharides: A Comparative Electrospray Ionization Study of Doubly and Singly Charged Complexes. J. Am. Chem. Soc. Mass Spectrom. 1997, 8(1), 32-42.

10. König, S.; Leary, J.A. Evidence for Linkage Position Determination in Cobalt Coordinated Pentasaccharides Using Ion Trap Mass Spectrometry. J. Am. Chem. Soc. Mass Spectrom. 1998, 9, 1125-1134.

11. Reinhold, V. N.; Reinhold, B. B.; Costello, C. E. Carbohydrate Molecular Weight Profiling, Sequence, Linkage, and Branching Data: ES-MS and CID. Anal. Chem. 1995, 67(11), 1772-1784.

12. Weiskopf, A. S.; Vouros, P.; Harvey, D. J. Characterization of Oligosaccharide Composition and Structure by Quadrupole Ion Trap Mass Spectrometry. Rapid Commun. Mass Spectrom. 1997, 11, 1493-1504.

13. Viseux, N.; de Hoffmann, E.; Domon, B. Structural Assignment of Permethylated Oligosaccharide Subunits Using Sequential Tandem Mass Spectrometry. Anal. Chem. 1998, 70, 4951-4959.

14. Weiskopf, A. S.; Vouros, P.; Harvey, D. J. Electrospray Ionization-Ion Trap Mass Spectrometry for Structural Analysis of Complex N-Linked Glycoprotein Oligosaccharides. Anal. Chem. 1998, 70, 4441-4447.

15. Ahn, Y. H.; Yoo, J. S. Malononitrile as a New Derivatizing Reagent for High-Sensitivity Analysis of Oigosaccharides by Electrospray Ionization Mass Spectrometry. Rapid Commun. Mass Spectrom. 1998, 12, 2011-2015.

16. Charlwood, J.; Langridge, J.; Tolson, D.; Birrell, H.; Camilleri, P. Profiling of 2-Aminoacridone Derivatized Glycans by Electrospray Ionization Mass Spectrometry. Rapid Commun. Mass Spectrom. 1999, 13, 107-112.

17. Saba, J. A.; Shen, X.; Jamieson, J. C.; Perreault, H. Effect of 1-Phenyl-3-methyl-5-pyrazolone Labeling on the Fragmentation Behavior of Asialo and Sialated N-Linked Glycans under Electrospray Ionization Conditions. Rapid Commun. Mass Spectrom. 1999, 13, 704-711.

18. Shen, X.; Perreault, H. Electrospray Ionization Mass Spectrometry of 1-Phenyl-3-methyl-5-pyrazolone Derivatives of Neutral and N-Acetylated Oligosaccharides. J. Mass Spectrom. 1999, 34, 502-510.
19. Harvey, D. J. Electrospray Mass Spectrometry and Fragmentation of N-Linked Carbohydrates Derivatized at the Reducing Terminus. J. Am. Soc. Mass Spectrom. 2000, 11, 900-915.

20. Her, G. R.; Santikarn, S.; Reinhold, V. N.; Williams, J. C. Simplified Approach to HPLC Precolumn Fluorescent Labeling of Carbohydrates: N-(2-pyridinyl)glycosylamines. J. Carbohydr. Chem. 1987, 6(1), 129-139.

21. Li, D. T.; Her, G. R. Linkage Analysis of ChromophoreLabeled Disaccharides and Linear Oligosaccharides by Negative Ion Fast Atom Bombardment Ionization and CollisionalInduced Dissociation with B/E Scanning. Anal. Biochem. 1993, 211(2), 250-257.

22. Li, D. T.; Her, G. R. Structural Analysis of ChromophoreLabeled Disaccharides and Oligosaccharides by Electrospray Ionization Mass Spectrometry and High-Performance Liquid Chromatography/Electrospray Ionization Mass Spectrometry. J. Mass Spectrom. 1998, 33, 644-652.

23. Li, D. T.; Sheen, J. F.; Her, G. R. Structural Analysis of Chromophore-Labeled Disaccharides by Capillary Electrophoresis Tandem Mass Spectrometry Using Ion Trap Mass Spectrometry. J. Am. Soc. Mass Spectrom. 2000, 11, 292-300.

24. Garozzo, D.; lmpallomeni, G.; Spina, E.; Green, B. N.; Hutton, T. Linkage Analysis in Disaccharides by Electrospray Mass Spectrometry. Carbohydr. Res. 1991, 221, 253-257.

25. Mulroney, B.; Traeger, J. C.; Stone, B. A. Determination of Both Linkage Position and Anomeric Configuration in Underivatized Glucopyranosyl Disaccharides by Electrospray Mass Spectrometry. J. Mass Spectrom. 1995, 30, 1277-1283.

26. Gu, J.; Hiraga, T.; Wada, Y. Electrospray Ionization Mass Spectrometry of Pyridylaminated Oligosaccharide Derivatives: Sensitivity and In-Source Fragmentation. Biol. Mass Spectrom. 1994, 23(4), 212-217.

27. Okamoto, M.; Takahashi, K.; Doi, T. Sensitive Detection and Structural Characterization of Trimethyl( $p$-aminophenyl)-ammonium-derivatized Oligosaccharides by Electrospray Ionization-Mass Spectrometry and Tandem Mass Spectrometry. Rapid Commun. Mass Spectrom. 1995, 9, 641-643.

28. Wang, W. T.; LeDonne, N. C., Jr.; Ackerman, B.; Sweeley, C. C. Structural Characterization of Oligosaccharides by High-Performance Liquid Chromatography, Fast-Atom BombardmentMass Spectrometry, and Exoglycosidase Digestion. Anal. Biochem. 1984, 141(2), 366-381.

29. Suzuki, S.; Kakhi, K.; Honda, S. Comparison of the Sensitivities of Various Derivatives of Oligosaccharides in LC/MS with Fast Atom Bombardment and Electrospray Ionization Interfaces. Anal. Chem. 1996, 68, 2073-2083.

30. Kubelka, V.; Altmann, F.; Staudacher, E.; Tretter, V. März. L.; Hård, K.; Kamerling, J. P.; Vliegenthart, J. F. G. Primary Structures of the N-linked Carbohydrate Chains from Honeybee Venom Phospholipase $A_{2}$. Eur. J. Biochem. 1993, 213, 1193-1204.

31. Lai, C. C.; Her, G. R. Analysis of N-Glycosylation of Phospholipase $\mathrm{A}_{2}$ from Venom of Individual Bees by Microbore High PerformanceLiquid Chromatography/Electrospray MassSpectrometry Using an Ion Trap Mass Spectrometer. J. Chromatogr. B 2002, 766(2), 243-250.

32. Packer, N. H.; Lawson, M. A.; Jardine, D. R.; Redmond, J. W. A General Approach to desalting Oligosaccharides released from Glycoproteins. Glycoconj. J. 1998, 15, 737-747.

33. Domon, B.; Costello, C. E. A Systematic Nomenclature for Carbohydrate Fragmentations in FAB-MS/MS Spectra of Glycoconjugates. Glycoconj. J. 1988, 5(4), 397-409. 